\title{
The Multifaceted Nature of Tumor Microenvironment in Breast Carcinomas
}

\author{
Laura Annaratone ${ }^{a, b}$ Eliano Cascardi ${ }^{a, b}$ Elena Vissio ${ }^{a, b} \quad$ Ivana Sarotto $^{a}$ \\ Ewa Chmielik $^{c}$ Anna Sapino ${ }^{a, b}$ Enrico Berrino ${ }^{a, b}$ Caterina Marchiò ${ }^{a, b}$ \\ a Unit of Pathology, Candiolo Cancer Institute, FPO IRCCS, Candiolo, Italy; ${ }^{b}$ Department of Medical Sciences, \\ University of Turin, Turin, Italy; ${ }^{C}$ Tumor Pathology Department, Maria Sklodowska-Curie National Research Institute \\ of Oncology, Gliwice Branch, Gliwice, Poland
}

\section{Keywords}

Breast cancer · Immune cells · Tumor-infiltrating lymphocytes · Mutational load · Cancer-associated fibroblasts - Immunotherapy · Ligand 1 of programmed cell death protein 1

\begin{abstract}
Heterogeneity in breast carcinomas can be appreciated at various levels, from morphology to molecular alterations, and there are well-known genotypic-phenotypic correlations. Clinical decision-making is strictly focused on the evaluation of tumor cells and is based on the assessment of hormone receptors and of the HER2 status, by means of a combination of immunohistochemical and in situ hybridization techniques. The tumor microenvironment (TME) also shows a multifaceted nature stemming from the different actors populating the intratumoral and the peritumoral stroma of breast carcinomas. Of note, we have now evidence that tumor-infiltrating lymphocytes (TILs) are clinically meaningful as their quantification in the intratumoral stroma strongly correlates with good prognosis, in particular in triple-negative and HER2-positive breast cancer patients. Nevertheless, TILs are just one of the many actors orchestrating the com-
\end{abstract}

\begin{tabular}{ll}
\hline karger@karger.com & (c) 2020 The Author(s) \\
www.karger.com/pat & Published by S. Karger AG, Basel \\
& This article is licensed under the Creative Commons Attribution- \\
Narger & NonCommercial-NoDerivatives 4.0 International License (CC BY- \\
NC-ND) (http://www.karger.com/Services/OpenAccessLicense). \\
Usage and distribution for commercial purposes as well as any dis- \\
tribution of modified material requires written permission.
\end{tabular}

plexity of the TME, which is populated by immune and nonimmune cells (cancer-associated fibroblasts, cancer-associated adipocytes), as well as non-cellular components such as chemical inflammation mediators. In this review article we will overview the main features of the distinct cell compartments by discussing (i) the potential impact the TME may have on the prognostic stratification of breast cancers and (ii) the possible predictive value of some markers in the context of immunotherapy in light of the recent results of phase III studies in advanced and early triple-negative breast cancer patients.

(c) 2020 The Author(s)
Published by S. Karger AG, Basel

\section{Introduction}

Breast cancer is a heterogeneous disease composed of different subtypes with distinctive histological and molecular features. From a morphological standpoint, the diversity of breast cancer growth patterns is captured mainly by histological grade; nevertheless, the breast cancer stroma is also highly heterogeneous, and this may influence the clinical and radiological diagnosis of breast cancer. The 2019 WHO blue book describes the stromal 
structure of carcinomas of no special type (NST) as extremely variable [1]. Invasive carcinomas of NST are typically associated with a dense and hard stroma rich in cancer-associated fibroblasts (so-called CAFs) that frequently show myofibroblastic differentiation. In other cases, the stroma is fibrotic with scant cellularity. Angiogenesis is generally marked around the tumor mass and readily outlined by specific endothelial markers. In contrast, invasive lobular carcinomas (ILC) generally present with little host reaction or disturbance of the background architecture, which renders its radiological and macroscopical identification quite difficult. This corresponds to an almost normal stroma. Luminal ILC is reported to have a more proliferative CAF population ( $\alpha$-smooth muscle actin positive) compared to luminal NST carcinomas; angiogenesis is also more prominent, although vessels are generally less mature [2]. Finally, there are some special histological types showing unique stromal features, such as mucinous carcinomas and micropapillary carcinomas. Mucinous carcinomas feature cell clusters floating in lakes of mucin partitioned by delicate fibrous septa containing capillary blood vessels [1]. Micropapillary carcinomas display a spongy stroma, characterized by clear and empty spaces around the cell clusters and a delicate stromal framework composed of fibroblasts and connective tissue [1].

At present, clinical decision-making is based on the evaluation of tumor cells and on the assessment of hormone receptors (estrogen [ER] and progesterone [PR] receptors) and of the epidermal growth factor receptor 2 (HER2) status, by a combination of immunohistochemi$\mathrm{cal}$ and in situ hybridization techniques. Of note, these analyses are strictly focused on the evaluation of tumor cells. Nevertheless, we are coming to terms that some cellular elements populating the stroma, typically immune cells, may impact on prognosis and even prediction of response to specific therapies. For instance, tumor-infiltrating lymphocytes (TILs) have reached level I evidence as a good prognostic factor in triple-negative (TNBC) and HER2-positive breast carcinomas and are now being incorporated in diagnostic practice [3, 4]. TILs are just one of the many actors orchestrating the complexity of the tumor microenvironment (TME), which is populated by a heterogeneous group of immune and non-immune cells, but also non-cellular components such as chemical inflammation mediators, which are often involved in several metabolic pathways [5], immune-evasion strategies [6] and immunotherapy response [7].

In this review article we will overview the main features of the distinct cell compartments by discussing (i) the po- tential impact the TME may have on the prognostic stratification of breast cancers and (ii) the possible predictive value of some markers in the context of immunotherapy.

\section{Tumor-Infiltrating Lymphocytes}

Tumor-infiltrating lymphocytes (TILs) are defined as mononuclear immune cells that infiltrate tumor tissue [8] and constitute a continuous variable quantified as a percentage of area occupied by TILs/total stromal area on hematoxylin- and eosin-stained tumor sections [8] (Fig. 1). Recommendations by a panel of experts of the International Immuno-Oncology Biomarker Working Group on Breast Cancer [9] have been provided and constitute the reference to follow to correctly report TILs [1, 8]. A training website has also been developed (www. tilsinbreastcancer.org).

A cut-off comprised between 50 and $60 \%$ of stromal area infiltrated by TILs has been largely used to define lymphocyte-predominant breast cancers (LPBCs) (Fig. 1), which account for about $11 \%$ of all invasive breast carcinomas [10]. TILs are more frequently observed in high-grade lesions, in TNBC and HER2-positive breast carcinomas [11-13]. In a recently reported cohort of breast carcinoma patients treated with neoadjuvant chemotherapy, TIL mean values for TNBCs, HER2-positive carcinomas and luminal carcinomas were reported as $28.5,26.5$ and $24 \%$, respectively [14].

There are solid data supporting the association between high degree of TIL infiltration and good outcome in triple-negative and HER2-positive disease [10, 12, 1517]. High levels of TILs correlate also with high pathological complete response (pCR) rates in the neoadjuvant setting in triple-negative $[18,19]$ and HER2-positive disease $[19,20]$. Taken together, the evidence provided so far supports the assessment of TILs as a robust prognostic factor in TNBC and HER2-positive breast carcinomas treated with chemotherapy with level I evidence provided by the multiple retrospective analyses of prospective clinical trial samples [4]. Therefore, it is not surprising that the latest 2019 WHO classification of breast tumors has acknowledged the importance of stromal response patterns and in particular the relevance TILs are gaining as a prognostic marker [1]. In addition, an invasive carcinoma of NST with medullary pattern (or basal-like features) rather than the historical medullary carcinoma has been proposed [1]. In other words, medullary carcinomas are now best considered as part of a spectrum of TIL-rich breast cancers. 

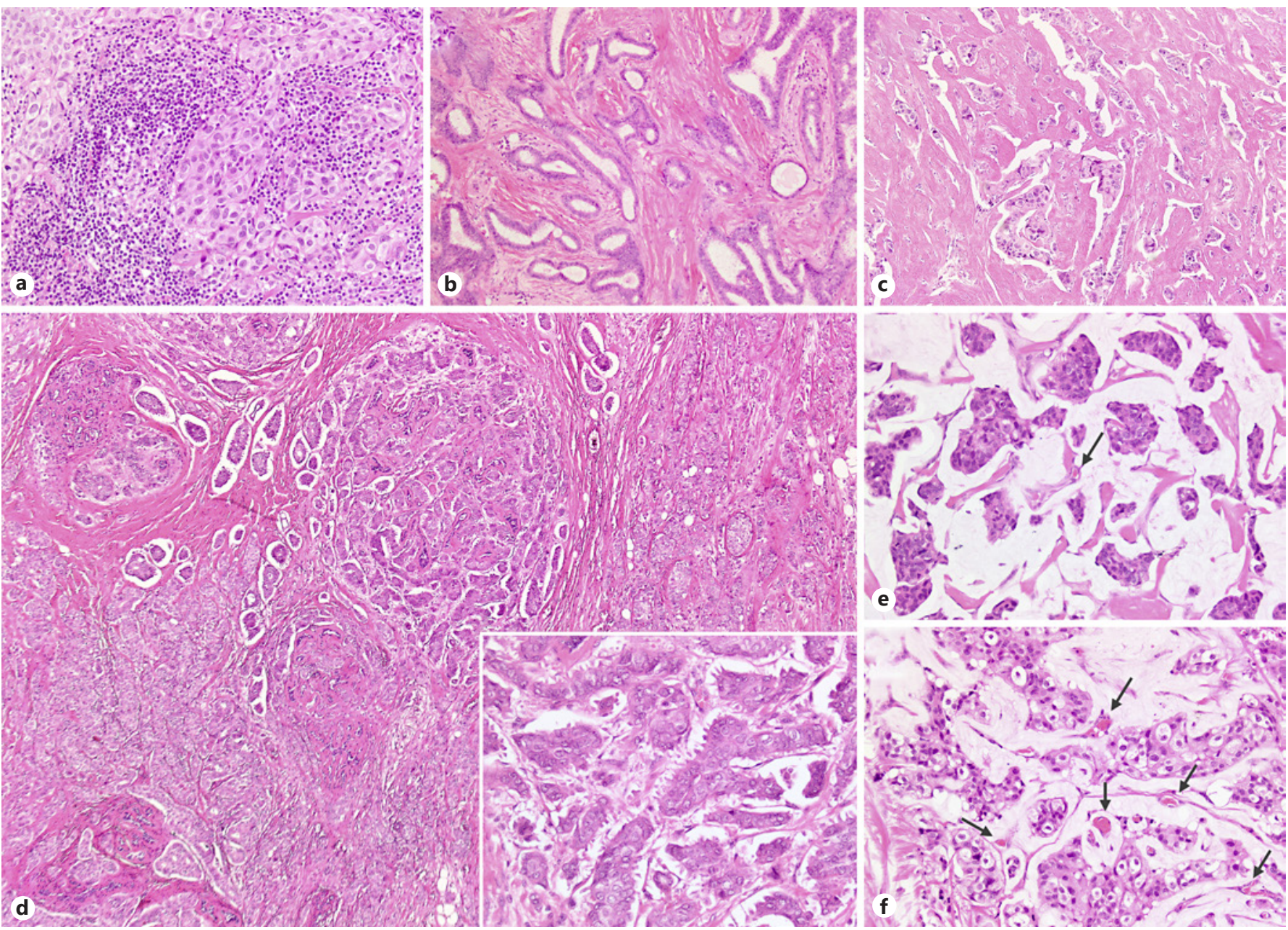

Fig. 1. An overview of the heterogeneity of stromal features across different breast carcinomas, including special histological types. a An example of immune-enriched cancer (so-called lymphocytepredominant breast cancer) with $>90 \%$ of stroma occupied by tumor-infiltrating lymphocytes (TILs): the tumor cells aggregate in a solid growth pattern and show high nuclear grade. b A well-differentiated tubular carcinoma showing dense fibroblastic stroma and rare TILs interspersed in the intratumoral stroma $(<5 \%)$. c An
NST (no special type) carcinoma displaying a dense fibrosclerotic immune-desert stroma. d An example of intratumor heterogeneity in breast cancer with a mixed carcinoma showing opposite stromal features in the two components: fibrosclerotic stroma in the NST component colliding with the typical spongy stroma of the micropapillary component (inset). e, $\mathbf{f}$ The unique stroma of mucinous carcinomas is composed by a lake of mucin, which is typically immune depleted and comprises tiny vessels (arrows).
Of note, a recent analysis of the prognostic value of TILs in surgically resected TNBC patients not treated with chemotherapy in the adjuvant setting has shown that a cut-off of $30 \%$ of TILs was able to identify patients with extremely good outcome, in the entire population and in stage I disease patients [21]. In addition, another analysis on the value of TIL evaluation in the context of HER2-positive disease has been reported for the ShortHER study: patients with low TILs appeared to benefit from 1-year trastuzumab, whereas patients affected by tumors with high TILs did extremely well with both 1 year and 6 months of trastuzumab-containing chemotherapy [22].

Taken together, these recent data may suggest possible strategies of chemotherapy de-escalation in specific subsets of patients.

Although the wealth of data on TILs in breast carcinomas seems quite robust, controversies and open questions remain to be answered.

First, we have not completely teased out the reasons behind a more immunogenic nature of TNBC and HER2positive carcinomas versus luminal carcinomas. More- 
over, in the most frequent special histological type of breast cancer, invasive lobular carcinoma, TILs have shown an inverted pattern in terms of correlation with outcome, as they appear to be significantly associated with a dismal prognosis [12].

Second, a controversy remains concerning the association between high levels of TILs and increased trastuzumab benefit in HER2-positive disease. Data from the FinHER trial showed for each $10 \%$ increase in TILs a significant decrease in distant recurrence rates in patients randomized to the trastuzumab arm [16]. On the other hand, analysis of TILs in the N9831 adjuvant trial in patients with early-stage HER2-positive breast cancer showed that the presence of TILs was prognostically associated with recurrence-free survival in patients treated with chemotherapy, but not in patients treated with trastuzumab-containing chemotherapy [23].

Third, we should mention that in diagnostic practice we assess TILs on a mere count on morphological grounds, which is cost-effective and has an acceptable yet not brilliant reproducibility [24-26]. Moreover, TILs represent a heterogeneous aggregate of immune cells with different phenotypes, and each subtype plays a different role in inflammatory responses (Fig. 2).

T-lymphocytes (CD3+) are the main component of TILs [27, 28]. T-lymphocytes include CD4+, CD8+ and T-regulatory cells (Treg). CD4+ and CD8+ T-cells represent the most significant anti-tumor cells [29, 30]: CD8+ T-lymphocytes recognize specific tumor antigens such as MHC-I and exert anti-tumor activity in TME through the pro-inflammatory interferon- $\gamma($ IFN- $\gamma)$ and granzymeperforin complex releases [31]; CD4+ T-lymphocytes are able to differentiate into specific effectors, including Thelper-1 (Th1)(secreting IL-2, IFN- $\gamma$ and IFN- $\alpha$ which increase the anti-tumoral activity of macrophages and natural killer, NK, cells) [32] and T-helper-2 (Th2) (secreting IL-4, IL-5, IL-6, IL-10 and IL-13 which increase the pro-tumoral activity of macrophages) [32]. Effectively, TILs CD8+ and Th1 cytokines correlate with a favorable prognosis in many cancer types [33-35], whereas high levels of Treg cells in breast carcinomas are associated with an unfavorable prognosis [36-38]. Treg cells suppress T-cell activation [36], IFN- $\gamma$ production [39] and the anti-tumor immune response. In addition, the association between an increase in Treg-circulating cells and breast cancer metastasis has been described [40].

A minor component of TILs is represented by B-lymphocytes and plasma cells, adaptive immune-system cells [41] whose presence in the TME has been identified in many cancer types [42, 43], including breast cancer [44].
B-cells have been reported in some studies to be found in up to $25 \%$ of all breast carcinomas [45-48], and they are often found in tertiary lymphoid structures with CD4+ and CD8+ T-cells and dendritic cells [49-51]. Similarly to T-cells, B-cells have been implicated in favorable survival rates in medullary breast cancer $[52,53]$ and common forms of breast cancer [54]. It has been reported that the inflammatory infiltrate associated with "medullarylike carcinomas" contains also plasma cells of the IgA immunophenotype, in analogy to those described in normal breast tissue and in contrast to the few plasma cells of infiltrating ductal carcinoma that were found to be predominantly of the IgG type. It has been supposed that likely in all secretory organs, such as salivary glands, and the gastrointestinal tract, the microenvironment in mammary glands is capable of attracting IgA precursors or IgA plasma cells. The predominance of IgA plasma cells in the majority of medullary carcinoma has been supposed to be a sign of a better functional preservation of this tumor [55].

Yeong et al. [56] used immunohistochemistry coupled with NanoString measurement of mRNA expression of immunoglobulin metagenes to quantify tumorinfiltrating B-cells and plasma cells in TNBC samples. The authors used CD38 antibodies to discriminate plasma cells within tumors, as CD138 immunocytochemical staining was also present on tumor cells. Multivariate analysis revealed that TNBCs with high intratumoral CD38+ plasma cell density were associated with longer disease-free survival independently of clinicopathological parameters, and of the densities of tumor-infiltrating T-cells and B-cells. Immunoglobulin gene IGKC, IGHM and IGHG1 mRNA expression correlated specifically with the density of CD38+ plasma cells. After adjusting the multivariate analysis for the effect of intratumoral CD38+ plasma cell density, the expression levels of all three genes lost the significant prognostic value, suggesting a biologically important role of plasma cells. Of the three genes tested, IGHG1 conferred the highest added prognostic value for both disease-free survival and overall survival (OS), when coupled with CD38+ plasma cell density [56].

\section{Inflammation, TILs and Tumor Mutation Burden}

The tumor mutation load or tumor mutation burden (TML or TMB) is defined as the number of non-synonymous mutations somatically occurring in a tumor, potentially generating neoepitopes that are able to improve the 


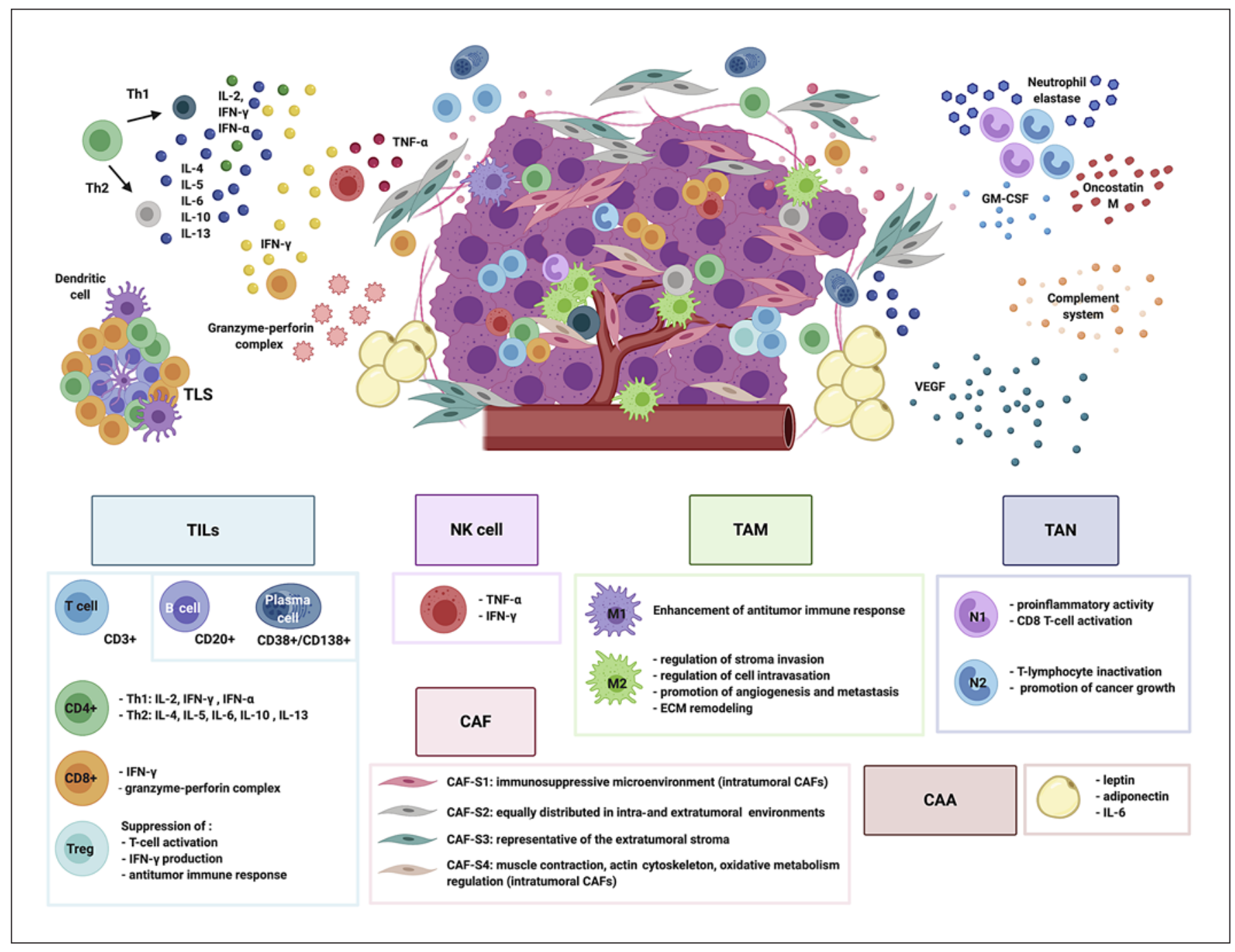

Fig. 2. The tumor microenvironment (TME) in breast carcinomas. The picture summarizes the different cellular immune and noncellular components of the TME in breast carcinomas. Tumorinfiltrating lymphocytes (TILs) are mainly represented by T-cells (CD3+) and include CD4+, CD8+ and T-regulatory cells (Treg). A minor component of TILs is represented by plasma cells and Bcells, usually found in tertiary lymphoid structures (TLS) with CD4+ and CD8+ T-cells and dendritic cells. Natural killer (NK) cells secrete cytokines such as TNF- $\alpha$ (tumor necrosis factor) and interferon- $\gamma$ (IFN- $\gamma)$. Tumor-associated macrophages (TAMs) are able to polarize into different phenotypes, M1 and M2. Tumorassociated neutrophils (TANs) can polarize into two distinct subtypes: N1 TANs and N2 TANs. TANs are able to release neutrophil elastase. In addition, neutrophil-derived oncostatin $\mathrm{M}$, released by granulocyte-macrophage colony-stimulating factor (GM-CSF)- stimulated TANs, can induce breast cancer cell detachment. Cancer-associated fibroblasts (CAFs) are classified into four subtypes (CAF-S1 to CAF-S4). CAF-S1 and CAF-S4 types are intratumoral CAFs, CAF-S3 are representative of the extratumoral stroma and CAF-S2 are equally distributed in both environments. Cancer-associated adipocytes (CAAs) are involved in tumor progression, metastasis and therapy resistance by secretion of adipokine such as leptin and adiponectin. Breast carcinomas need new blood vessels to maintain growth, ensure cell proliferation and fuel metastatic dissemination: vascular endothelial growth factor (VEGF) represents the most important pro-angiogenic factor, released by multiple TME components. The complement, a crucial part of the innate immune system, has emerged as a major regulator of cancer immunity. Complement anaphylatoxins in the TME can exert a pro- and anti-tumorigenic potential. 
stimulation of the immune system against the tumor cells, recognized as carriers of "non-self" antigens.

Among all cancers, breast carcinomas are characterized by an intermediate level of TMB [57], which is higher in TNBC and HER2-positive carcinomas compared to luminal carcinomas [58]. The mutation rate is the key value defining TMB, calculated as the number of mutations per mega-base of a genome. This can be devised by whole exome sequencing (WES) data (cumbersome in routine diagnostic practice) or from more feasible targeted panels, with a longitudinal coverage higher than 1.3 Mb in size (reviewed in Fancello et al. [59]). There is not a unique cut-off limit used to discern between high-TMB and low-TMB tumors: as pointed out by Samstein et al. [60] the right TMB cut-off cannot be completely gene panel-, histology- and clinical question-agnostic.

Syllogistic simplifications virtually relate the number of immunogenetic mutations with recruitment of intratumoral lymphocytes, and a positive correlation between $\mathrm{TMB}$ and immune infiltration has been initially reported across different tumor entities, including breast cancer [61]. However, recent works decouple this association in most neoplasms $[62,63]$, and this holds true also for breast carcinomas [64-66]. In these studies, the degree of immune cell enrichment was not evaluated by TIL raw counts, rather this information was extrapolated from analyses of immunophenotypic gene expression profiles (GEPs), obtained by using either RNA-sequencing [64] or RNA-based NanoString targeted panels [62]. Spranger et al. [63] exploited the TCGA dataset to correlate the immune infiltration landscape with the number of genomic mutations focusing on melanomas, but also reporting GEPs and mutation count for about 10,000 tumors, comprising a total number of 1,067 breast carcinomas. They stratified cases into non-inflamed, intermediate or inflamed tumors, taking into account a T-cell gene signature of 13 genes. Interestingly, the three inflammation groups did not significantly differ in terms of TMB, suggesting that mutation densities are not directly correlated with T-cell enrichment [63]. Similarly, a weak association between a different expression signature of 18 genes associated with T-lymphocytes and TMB values has been reported by Cristescu et al. [62], with an in silico analysis on the same TCGA database. In addition, the authors applied this signature on a selected cohort of patients who were subjected to pembrolizumab treatment from different clinical trials, including also ER-positive/HER2-negative and TNBC patients. From the so-called Pan-Cancer cohort (without a discrimina- tion in terms of tumor type) they introduced a new concept, in which a joint stratification through the combination of a high TMB and a high T-cell phenotype identified a subset of "super-responder" patients with a higher progression-free survival (PFS) compared to that obtained when the two single parameters were considered alone [62]. In this context, when samples from the TCGA cohort were stratified using the three classes $\left(\mathrm{TMB}_{\text {low }} /\right.$ $\mathrm{T}-\mathrm{Cell}_{\text {low }}, \mathrm{TMB}_{\text {high }} / \mathrm{T}-\mathrm{Cell}_{\text {high }}, \mathrm{TMB}_{\text {high }} / \mathrm{T}-\mathrm{Cell}_{\text {high }}$ ) about $50 \%$ of breast carcinomas with a HER2-positive or a triple-negative phenotype clustered in the subset with at least high TMB or high T-cell phenotype but only a minority showed a concomitant high $\mathrm{TMB} /$ high $\mathrm{T}$-cell phenotype [62].

More specifically, in breast cancer, RNA sequencingbased immune metagenes have been shown to significantly correlate with lower clonal heterogeneity in all subtypes and with a trend for lower overall mutation, neoantigen and copy number alteration loads in TNBC and HER2-positive cancers [66]. Conversely, in ER-positive carcinomas mutation load, neoantigen load and copy number alteration load were weakly but positively associated with immune infiltration, which reached significance for overall mutation load only [66].

In TNBCs Karn et al. [65] found RNA sequencingbased immune metagenes to correlate well with histological TILs quantification and to be inversely associated with clonal heterogeneity and somatic copy number alteration levels. In addition, lymphocyte-rich TNBCs harboring a good prognosis had significantly lower mutation and neoantigen counts than did lymphocyte-poor TNBCs with poor prognosis. Taken together, these data may lead to hypothesize that immune-rich TNBCs may be under an immune surveillance that continuously eliminates many immunogenic clones, resulting in lower clonal heterogeneity [65].

Still based on RNA-sequencing data, Thomas et al. [67] classified samples of TCGA and METABRIC breast cancer cohorts according to the level of infiltration (hot, warm and cold tumors) and observed an improved overall survival for patients with high $\mathrm{TMB} /$ hot tumors, regardless of type of therapy. They confirmed higher levels of both TMB and immune cell infiltration in ER-negative patients; however, they observed an antithetical behavior for luminal and the triple-negative carcinomas: the worst survival curve for TNBC patients was characterized by a high mutation rate but a low infiltrate expression signal, whereas the best overall survival was observed in high $\mathrm{TMB} /$ hot luminal A carcinomas [67]. 


\section{Natural Killer Cells}

Natural killer (NK) cells are cytotoxic lymphocytes participating in innate immunity that efficiently recognize and kill tumor cells through several mechanisms including the expression of ligands for NK cell-activating receptors on target cells (Fig. 2). Activated NK cells secrete a wide variety of cytokines such as TNF-a (tumor necrosis factor) and IFN- $\gamma$ [68] and exert a cellular cytolytic effect through the liberation of granzymes and cytotoxic perforins [69]. A recent meta-analysis has shown that breast cancer displayed variable expression of ligands for NK cell receptors, in particular NKG2D ligands and DNAM1 ligands [70]. A better survival for patients showing higher expression of NCR3 (NKp30), NCR1 (NKp46), CD96, CRTAM, DNAM1 and NKG2D was also reported $[71,72]$.

Verma et al. [73] analyzed a series of breast cancer patients with locally advanced carcinomas subjected to neoadjuvant chemotherapy and observed an association between increased NK cells in the blood and better pathological responses. No differences in terms of NK cell population were observed in tissue specimens before and after treatment. On the other side, in HER2-positive carcinomas treated with trastuzumab-containing chemotherapy Muntasell et al. [74] observed that baseline tumor-infiltrating NK cells were significantly associated with pCR. In addition, molecular signatures associated with NK cells seem to represent a predictive marker of relapse-free survival in breast carcinomas [75], and upregulation of GZMB, PRF1, NCR1, KIRs and KLRCs were also associated with breast cancer patient outcome [76].

It should be acknowledged that when tumors develop mechanisms of immune evasion, some of these mechanisms include also downregulation of NK cell ligands such as NKG2D and DNAM1 receptors, which can therefore lead to inhibition of NK cell functions [77-80].

\section{Macrophages}

Macrophages are large mononuclear cells that belong to the phagocyte system and are one of the immune cell types more abundantly present in breast cancer TME [81] where they play a key role in tumor progression, immunosuppression and therapy resistance [82-85] (Fig. 2). Tumor-associated macrophages (TAMs) display great plasticity and polarize into different phenotypes: classically activated (M1) and alternatively activated (M2) macrophages. The first one is polarized by Th1 cells and

Breast Cancer Microenvironment triggers anti-tumor immune responses [86]. Conversely, M2 macrophages are stimulated by Th2 cytokines such as transforming growth factor $\beta_{1}$ (TGF- $\left.\beta_{1}\right)$, IL- 4 and IL-13 [87], which activate STAT6 target genes [88] (suppressing immune system functions) and promote tumor cell proliferation. M2 TAMs are the most frequent type in breast cancers [89] since during carcinogenesis TME most likely drives M1 to the M2 phenotype [90]. It is well known that macrophages are recruited to the tumor by a range of chemokines (including vascular endothelial growth factor, VEGF, and C-C chemokine ligand 2) and foster breast cancer progression in different ways: regulating stroma invasion and cell intravasation [91, 92], promoting angiogenesis [93] and metastasis [94, 95], and remodeling extracellular matrix (ECM) by metalloproteinase secretion [96]. Sousa et al. [97] reported a strong association between M2 levels and poor cancer differentiation, ER-negative and basal-like subtypes. Moreover, many other studies have described a correlation between TAMs and higher histological grade, hormone receptornegative status, advanced stages and worse outcome [98, 99]. Interestingly, bisphosphonate drugs, used in combination with hormonal therapy for breast cancer treatment, are also known to exert an anti-macrophage activity [100]. In a study of postmenopausal women with luminal carcinomas and receiving bisphosphonates disease recurrence and mortality were significantly reduced compared to the patients who did not receive bisphosphonate therapy [101].

\section{Neutrophils}

Neutrophil granulocytes represent $50-70 \%$ of the leukocytes present in human blood [102] and their ability to phagocytize and degrade external pathogens [103] is one of the characteristics that makes neutrophils the main cells of innate immunity. Neutrophils can efficiently migrate to inflammatory sites due to the action of different factors. They are also present in numerous cancer models and in the TME (tumor-associated neutrophils, TANs) where they play an important role in pro- and anti-tumorigenic processes [104, 105] (Fig. 2). Similarly to macrophages, neutrophils can polarize in two distinct subtypes with opposite functions: N1 TANs show pro-inflammatory activity and induce CD8 T-cell activation, whereas N2 TANs inactivate T-lymphocytes [105] and promote cancer growth.

Albrengues et al. [106] described the mediator role of neutrophils in neoplastic progression by converting dis- 
seminated dormant tumor cells in metastatic cells in a murine model. This process is the result of neutrophil elastase (NE) and matrix metalloproteinase-9 (MMP-9) action on laminin, which induce the proliferation of dormant tumor cells by $\alpha 3 \beta 1$-integrin activation [106]. Additionally, in an in vitro co-culture model the authors were able to demonstrate the ability of neutrophil-derived oncostatin M, released by GM-CSF-stimulated neutrophils, to induce breast cancer cell detachment, promote the invasiveness capacity of MDA-MB-231 and T47D human breast cancer cells and induce breast cancer progression [107]. In this scenario, TANs may represent a source of oncostatin $\mathrm{M}$ for cancer cells, resulting in oncostatin $\mathrm{M}$-induced tumor progression and metastasis. In fact, the authors suggested that GM-CSF, released by breast cancer cells, stimulates neutrophils in producing oncostatin $\mathrm{M}$ and storing it in granules. Cell-to-cell contact between neutrophil and breast cancer cells causes the release of oncostatin $\mathrm{M}$ from TANs, its binding to oncostatin $\mathrm{M}$ receptors on breast cancer cells, increasing cell detachment, triggering tumor cell proliferation via activation of STAT3, VEGF secretion and invasiveness [107].

Recently, neutrophils have also been shown to be important for the survival and transport of circulating tumor cells (CTCs) in blood vessels, by formation of CTCneutrophil clusters $[108,109]$, which probably protect CTCs facilitating their migration in other tissues [106, 110, 111]. CTC-neutrophil clusters are characterized by a different genetic profile compared to CTCs alone, which makes them efficient metastatic precursors [108]. In fact, CTCs isolated from the CTC-neutrophil clusters present an increase in cellular replication capacity (also confirmed by higher levels of Ki-67) and a marked expression of the genes that code for TNF- $\alpha$, OSM, IL- $1 \beta$ and IL- 6 [108].

Current evidence indicates that an increased neutrophil-to-lymphocyte ratio (NLR, obtained dividing the serum neutrophil count by the lymphocyte count) assessed in blood samples, can have a predictive value for breast cancer patients not only in the early setting but also in the metastatic setting: the inflammatory status upon initial treatment, resumed by NLR values, is associated not only with a high recurrence rate, but also with the survival outcome following recurrence [112]. Therefore, monitoring the NLR during the follow-up period may lead to early detection of patients who potentially have a higher risk of recurrence. In addition, Iwase et al. [112] demonstrated that TNBC had a significantly higher NLR at the time of recurrence and the highest change (an increase of 2.0) compared with the other subtypes.
Several studies and a recent meta-analysis have confirmed and extend the prognostic role of NLR in breast cancer [113-115]. However, Ferroni et al. [115] demonstrated that the NLR may represent a negative prognostic factor to define distant metastasis-free survival, especially in stage I breast cancer, but not for local recurrence. Following their suggestions, the NLR prognostic value should be regarded with caution, and additional studies are required to consolidate the clinical value of NLR. Nevertheless, in stage I patients the presence of a high NLR might raise the question as to whether they should be more aggressively managed [113-115]. Furthermore, a retrospective study was performed to investigate the role of NLR in breast cancer patients receiving neoadjuvant chemotherapy [116]: the pCR rate in patients with low pre-treatment NLR (NLR <2.06) was higher than in those with higher NLR (NLR $\geq 2.06$ ) (24.5 vs.14.3\%, $p<0.05)$. In addition, high NLRs were an independent significant predictor of lower relapse-free survival and breast cancer-specific survival in patients undergoing pre-operative chemotherapy.

\section{Immunotherapy in Breast Cancer}

Immunotherapy-based approaches in breast cancer have only recently gained strong evidence to enter clinical practice, and this is particularly true for TNBCs. In this context, the use of TILs and of other biomarkers of immunogenicity such as ligand 1 of programmed cell death protein 1 (PD-L1) expression seem to be playing a role in the prediction of response [117]. PD-L1 is the ligand 1 of the programmed cell death protein 1 (PD-1), which represents the predominant checkpoint present on both CD8+ and CD4+ T-cells. The results of the IMpassion 130 phase III study showed a clinical benefit from addition of atezolizumab (a monoclonal antibody targeting PD-L1) to nab-paclitaxel in patients with locally advanced/metastatic TNBCs [118]. The median PFS was 7.5 months in the atezolizumab plus nab-paclitaxel arm versus 5 months in the placebo plus nab-paclitaxel $\operatorname{arm}(p<0.0001)$ [118]. There was no significant difference in overall survival between the treatment groups in the intention-to-treat population; however, the data suggested a clinically meaningful OS benefit with atezolizumab plus nab-paclitaxel in patients with PD-L1-positive status. A significant predictor of response was indeed identified in PD-L1 expression in immune cells in more than $1 \%$ of the tumor area (Fig. 3). Thanks to these results in 2019 the US Food and Drug Administration has granted accelerated approval to 


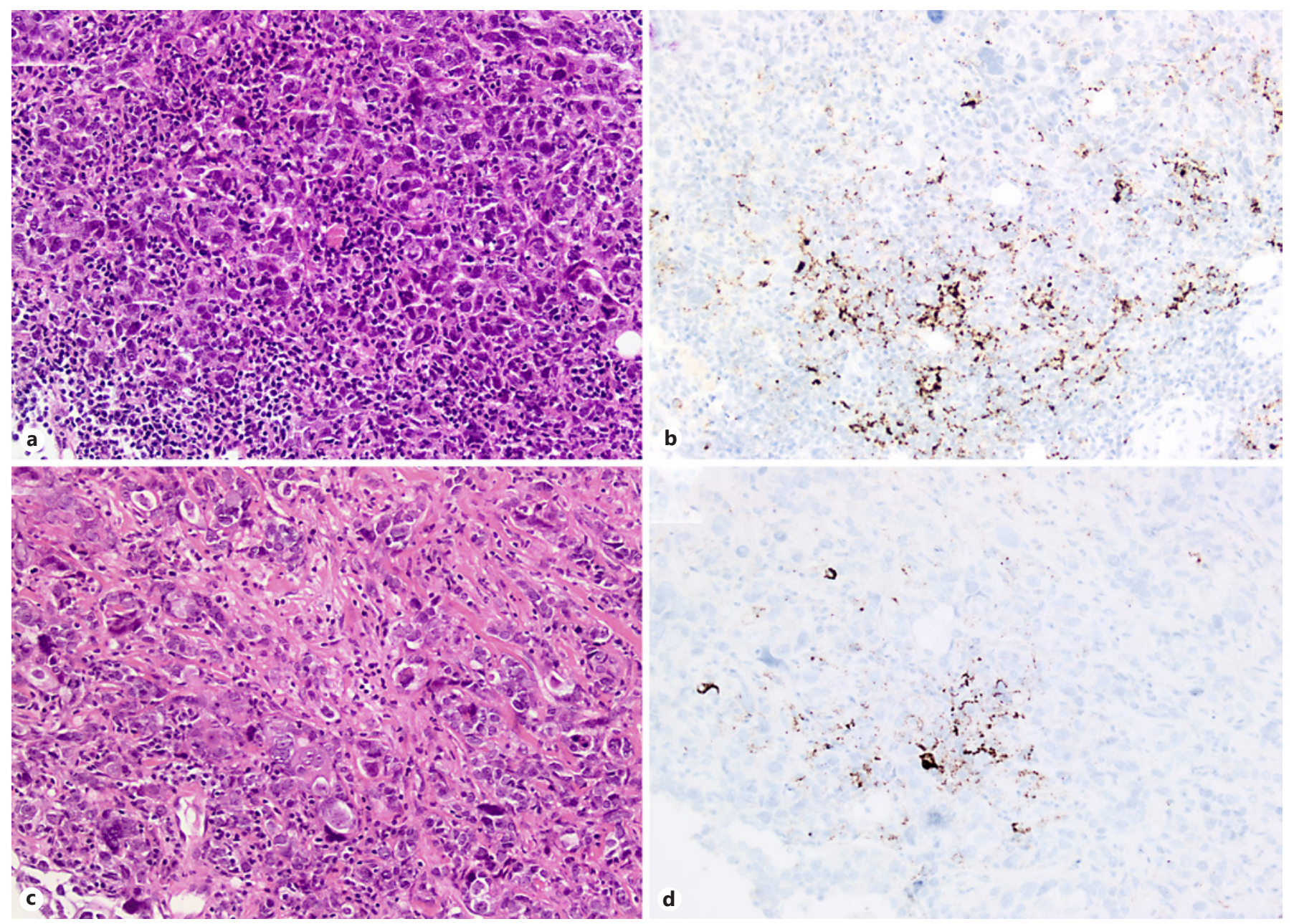

Fig. 3. Core biopsies of relapsed invasive breast carcinomas of no special type (NST) of triple-negative phenotype $(\mathbf{a}, \mathbf{b})$ assessed for PD-L1 expression by the SP142 assay $(\mathbf{b}, \mathbf{d})$ : note in both cases the typical punctuate dark brown staining of immune cells.

atezolizumab plus nab-paclitaxel as a first-line treatment for patients with unresectable locally advanced or metastatic TNBCs showing PD-L1 expression on immune cells covering $1 \%$ or more of the tumor area (PD-L1 immune-cell positive) [119]. More recently, the European Commission has also approved the combination of atezolizumab plus nab-paclitaxel for the treatment of unresectable locally advanced or metastatic TNBC patients with tumors that are $\mathrm{PD}$-L1 positive ( $\geq 1 \% \mathrm{PD}$-L1 expression) who have not received previous chemotherapy for metastatic disease [120].

A key point is represented by the scoring system of PD-L1 expression and the assay that was used for the immunohistochemical test. Contrarily to other neoplastic diseases such as lung cancer, PD-L1 expression in breast cancer is mainly expressed in immune cells populating the stroma (prevalence of $41 \%$ of cases) rather than in tumor cells (Fig. 3), where it can be rarely appreciated (less than $10 \%$ of cases) [118]. Since PD-L1 is mainly expressed in immune cells (ICs), it is not surprising that breast carcinomas with a certain degree of TILs are those likely to show PD-L1 expression. Nevertheless, PD-L1 can also be expressed by macrophages, neutrophils and dendritic cells. Indeed, in the IMpassion130 study PD-L1 expression was quantified in the whole immune cell compartment, and the data show that the presence of PD-L1 in immune cells rather than mere TILs quantification or $\mathrm{CD} 8+$ phenotyping positively correlated with response: patients with TIL-positive tumors derived clinical benefit (in terms of PFS) only if their tumors were also PD-L1 
Table 1. Ligand 1 of programmed cell death protein 1 (PD-L1) quantification by immunohistochemistry in triple-negative breast carcinomas (TNBCs): summary of different scoring methods applied in different clinical studies

\begin{tabular}{|c|c|c|c|}
\hline & Combined positive score (CPS) & Immune cell (IC) algorithm & Immune cell (IC) algorithm \\
\hline Antibody clone & 22C3 (Dako Agilent) & SP142, SP263 (Roche-Ventana) & SP263 (Roche-Ventana) \\
\hline Formula & $\begin{array}{l}\text { (Number of PD-L1 staining cells } \\
\text { (tumor cells, lymphocytes, } \\
\text { macrophages)/the total viable tumor } \\
\text { cells) } \times 100\end{array}$ & $\begin{array}{l}\text { Any staining in immune cell/tumor } \\
\text { area (tumor area = area occupied by } \\
\text { tumor cells, associated intratumoral } \\
\text { and continuous peritumoral stroma) }\end{array}$ & $\begin{array}{l}\text { Any staining in immune cell/tumor } \\
\text { area (tumor area = area occupied by } \\
\text { tumor cells, associated intratumoral } \\
\text { and continuous peritumoral } \\
\text { stroma) }\end{array}$ \\
\hline Cut-off & $>1 \%$ & $>1 \%$ & $>1 \%$ \\
\hline Minimal requirement for testing & At least 100 viable tumor cells & $\begin{array}{l}\text { At least } 50 \text { tumor cells with viable } \\
\text { stroma }\end{array}$ & $\begin{array}{l}\text { At least } 50 \text { tumor cells with viable } \\
\text { stroma }\end{array}$ \\
\hline $\begin{array}{l}\text { Clinical study in which it was } \\
\text { originally applied } \\
\text { (immunotherapy combination } \\
\text { used in the experimental arm) }\end{array}$ & $\begin{array}{l}\text { KEYNOTE-522 (pembrolizumab } \\
\text { plus a sequence of carboplatin }+ \\
\text { paclitaxel followed by doxo/ } \\
\text { epirubicin }+ \text { cyclophosphamide) }\end{array}$ & $\begin{array}{l}\text { IMpassion130 (atezolizumab + nab- } \\
\text { paclitaxel) }\end{array}$ & \\
\hline $\begin{array}{l}\text { Analysis of specimens from } \\
\text { other studies }\end{array}$ & $\begin{array}{l}\text { Yes, post-hoc analysis of } \\
\text { IMpassion } 130 \text { samples }\end{array}$ & No & $\begin{array}{l}\text { Yes, post-hoc analysis of } \\
\text { IMpassion } 130 \text { samples }\end{array}$ \\
\hline
\end{tabular}

IC-positive; similarly, patients with CD8-positive tumors only derived clinical benefit if their tumors were also PDL1 IC-positive [121].

In IMpassion130, evaluation of both primary tumors and metastatic deposits was allowed, and no difference was observed in predicting response according to type of specimen evaluated [118]. Still we do not have data on direct comparison of paired primary tumor and metastatic sites from the same patient. From a post-hoc analysis performed on the study we know that immunogenicity may vary according to the metastatic site, with liver metastases displaying the lowest level of IC infiltration overall [122].

A major debate relates to the interchangeability of antiPD-L1 antibodies in diagnostic practice, a topic of major interest for pathologists. In the IMpassion130 study, the SP142 assay was used, and the Food and Drug Administration approved the drug with this specific companion diagnostic. Tumor specimens of the IMpassion 130 cohort have been further analyzed by means of two other clones used in diagnostic practice, the SP263 and the 22C 3 with corresponding scoring systems (Table 1 ). The $22 \mathrm{C} 3$ and the SP263 identify a larger number of positive cases (81 and $75 \%$, respectively) compared to SP142 (46\%), and a significant correlation with response to atezolizumab was observed also for all of the clones [122]. However, it is important to consider that the subpopulation of cases positive for SP263 and/or the 22C3 but negative for SP142 does not show PFS advantage in the atezolizumab arm, thus demonstrating that the clinical benefit observed for the other two clones is driven by the positive population that is identified by the SP142 clone [122]. In addition, the SP142 assay identified patients with the smallest hazard ratio point estimates and longest median PFS and OS from atezolizumab plus nab-paclitaxel [122].

In the context of immunotherapy approaches in breast cancer, it should also be acknowledged that results on early TNBCs treated in neoadjuvant studies with combination of chemotherapy and immunotherapy are now available. The phase III KEYNOTE-522 trial has recently shown significantly higher pCR rates for those patients treated with the addition of pembrolizumab to chemotherapy [123]. Although a higher pCR rate was observed for the PD-L1-positive tumors, the difference was not statistically significant. Of note, the PD-L1 evaluation in this study was carried out by using the combined positive score, which takes into account tumor and stromal cell expression (Table 1).

Taken together, on one side the available data highlight the efficacy of new therapeutic agents in a disease 
with high unmet needs (TNBC patients). On the other side, the possible biomarkers predicting response to treatment are yet to be fully elucidated, including the precise role of PD-L1 expression in relation to timing of expression (primary tumors vs. residual disease, relapses, metastatic deposits) and disparities among technical assays that may impact on patient selection.

\section{Cancer-Associated Fibroblasts}

Cancer-associated fibroblasts (CAFs) are the main cell component of the breast cancer stromal compartment, which is usually desmoplastic with some exceptions in histological special types of breast cancer such as micropapillary carcinomas, mucinous carcinomas or medullary-like carcinomas, thus highlighting a certain degree of heterogeneity also in the stromal compartment of breast cancer (Fig. 1).

CAFs are able to secrete a number of proteases, which enhance their ability to migrate and remodel ECM [124]; they have been shown also to secrete inflammatory molecules and growth factors, which are capable of recruiting inflammatory cells in neoplastic sites [125].

In a recent meta-analysis, a high density of fibroblasts was associated with worse clinical outcome, poor tumor differentiation and lymph node metastasis in breast carcinomas [126]. Moreover, collagen density can reduce the number of CD8+ TILs in breast tumors and modulate Tcell cytotoxic activity [127]. By using in vivo heterotypic cell recombinant models, Dumont et al. [128] demonstrated that CAFs can promote a mesenchymal phenotype acquisition both in pre-malignant and malignant mammary epithelial cells, and modulate dissemination, tumorigenesis and metastasis of breast cancer cells through deposition of a distinct ECM characterized by aligned collagen fibers/deposits. A recent study on mouse models of TNBC has shown that the hedgehog ligand produced by neoplastic cells mediates CAF reprogramming leading to stemness and chemoresistance via FGF5 expression and production of fibrillar collagen [129]. Interestingly, the use of smoothened inhibitors (SMOi) for stromal treatment on patient-derived xenografts seems to be able to mediate downregulation of cancer stem cell marker expression and to sensitize cells to taxanes that reduced metastatic disease and improved survival. These in vivo data, coupled with evidence from phase I studies of efficacy of the combination of SMOi and docetaxel, pose the preclinical bases for a potential new therapeutic target choice in TNBC patients [129].

Breast Cancer Microenvironment
Interestingly, Costa et al. [130] have recently identified distinct CAF subsets (S1-S4) in breast cancer stroma by means of multicolor flow cytometry and concomitant analysis of distinct fibroblast marker expression levels. CAF-S1 and CAF-S4 types are intratumoral CAFs and are more present in HER2-positive carcinomas and TNBCs, CAF-S3 cells are representative of the extratumoral stroma, and CAF-S2, equally distributed in both environments, are enriched in luminal A carcinomas. Furthermore, CAF-S1 and CAF-S4 show distinct genetic profiles and different characteristics: CAF-S4 seems to be responsible for muscle contraction, actin-cytoskeleton and oxidative metabolism regulation, whereas the CAF-S1 type is involved in ECM organization and contributes to the formation and maintenance of an immunosuppressive microenvironment by attracting and increasing the survival of CD4+ CD25+ T-cells, promoting T-cell differentiation into Treg and enhancing Treg-mediated inhibition of T effector proliferation [130]. Hence, breast carcinoma tumors enriched in CAF-S1 may acquire resistance to immunotherapies, and it can be postulated that CAF$\mathrm{S} 1$ molecules provide potential targets that may pave the way for additional treatment strategies.

\section{Cancer-Associated Adipocytes}

Adipocytes represent a relatively abundant component of breast parenchyma. Cancer-associated adipocytes (CAAs) differ from the normal adipocytes in size, metabolic activity and adipokines expression [131, 132] and have been demonstrated to be involved in tumor progression, metastasis and therapy resistance by secretion of adipokines, such as leptin and adiponectin, and a series of inflammatory chemokines and interleukins [133, 134]. For instance, the increased leptin secretions observed in CAAs can promote cell proliferation and tumor angiogenesis by upregulation of lysyl hydroxylase enzyme, activation of ER, JAK/STAT3, PI3K/AKT and SRC-1 signaling pathways, and by increasing cyclin D1 and VEGF/ VEGFR expression [132, 135]. Conversely, adiponectin (APN), which plays an anti-tumorigenic role by inducing apoptosis, suppressing growth and invasion of breast cancer cells through AMPK activation and PI3K/AKT inhibition, is decreased in CAAs [133]. An APN reduction was detected both in co-culture in vitro models and in CAAs located in human breast cancer tissues as compared with normal mammary adipose tissue [136].

Cruz et al. [137] observed in in vitro models that leptin also promotes the activation of focal adhesion kinase, 
thus contributing to cell-cell adhesion weakening and increasing the secretion of metalloproteases (MMP-2 and MMP-9) required for ECM remodeling and cell migration in TNBC cell lines. Another study has demonstrated that free fatty acids added to co-cultures of breast cancer cells and adipocytes were transferred to cancer cells, driving fatty acid metabolism, resulting in increased proliferation and cell migration [138]. The upgraded serum levels of leptin have also been associated with higher pathological grade and aggressive phenotypes in breast cancer patients [139]. Produced by adipose tissues, IL-6 is more secreted in CAAs compared with other adipocytes [131], and it has also been shown to promote cancer progression when adipocytes are co-cultured with breast cancer cells [140]. Furthermore, it has also been demonstrated that IL-6 production can regulate cancer cell survival, immune suppression and drug resistance by JAK phosphorylation and STAT3 activation [141]. Interestingly, it has been observed that PD-L1 expression in mature adipocytes negatively modulates the efficacy of immunotherapeutic agents in in vitro breast cancer models, by suppressing the antitumor-functions of CD8+ and CD4+ T-cells [142].

\section{Microvascular Density in TME}

Breast carcinomas need new blood vessels to maintain growth, ensure cell proliferation and fuel metastatic dissemination. A high microvascular density has been largely associated with adverse clinical-pathological features (large tumor size, high histological grade, lymph node metastasis and poor prognosis) [143-145]. A wealth of data supports a central role of multiple TME components in angiogenesis by releasing pro-angiogenic factors such as VEGF, acid and basic fibroblast growth factor, transforming growth factor- $\beta_{1}$, hypoxia-inducible factors (HIF-1 and HIF-2) and mast cell-derived metalloproteinases [146, 147].

VEGF represents the most important pro-angiogenic factor, shown to be over-expressed in several breast cancer models, and it has been correlated with OS in both node-positive and node-negative breast cancer [148, 149]; it has also been related with impaired response to tamoxifen or chemotherapy in advanced breast cancer patients [150]. VEGF receptor-2 (VEGFR-2) is the predominant form that controls angiogenesis, and the regulation of its expression has been investigated in several in vitro models with the aim of developing new pharmacological strategies to target cancer cell proliferation and survival [151]. Estrogen (E2) regulates VEGFR-2 in angiogenesis through complex mechanisms, involving both genomic and non-genomic effects. Higgins et al. [152] have demonstrated an E2-dependent down-regulation of VEGFR-2 expression in MCF-7 breast cancer cells, but also an E2-dependent stimulation of VEGFR-2 mRNA and protein expression in ZR-75 breast cancer cells [153]. In the latter scenario, it could be hypothesized that by blocking secretion of $\mathrm{E} 2$ angiogenesis would be inhibited [154].

Linderholm et al. [155] reported higher intratumoral VEGF levels and both shorter recurrence-free survival and OS in TNBC patients compared to non-TNBC subgroups.

Other factors contribute to increase the breast angiogenic microenvironment. For instance, recent studies showed that CCL2/CCR2 signaling in breast cancer cells regulates tumor growth and invasion by promoting angiogenesis through the recruitment and branching of endothelial cells, recruiting and polarizing macrophages to M2 phenotype, and suppressing cytotoxic T-cell activity [156]. Kim et al. [157] analyzed both the expression levels of Notch1, a signaling pathway involved in cell proliferation and angiogenesis, and microRNAs-34a in 114 TNBC samples and reported better OS in patients presenting low EC Notch1 (Notch1 microvascular density to CD34 microvascular density ratio) than those with a high ratio, and a significant correlation between high microRNAs34a levels, decreased vessel formation (low EC Notch1 levels) and higher survival benefit in a lymph-node-positive group [157].

The hypoxia is another pro-angiogenesis signal. HIF$1 a$, one of the major transcription factors that lead hypoxic cells to up-regulate proteins that promote survival and increase growth of hypoxic tumor cells, is expressed in BRCA1-2 carrier [158]. HIF-1 $\alpha$ is higher in poorly differentiated than in well-differentiated lesions, and its increased expression is also associated with increased expression of ER and VEGF [159]. IL-8, a chemotactic factor for neutrophils, is also known to be a powerful promoter of angiogenesis and, in oxidative stress states (such as inflammation conditions), IL- 8 can be produced by the activation of endothelial cells and showed a metastatic potential role, by mediating formation, in neutrophil-endothelial cell co-culture, of neutrophil extracellular trap (NET), also known as NETosis $[160,161]$. NETs can promote inflammatory progression in TME causing endothelial damage and activating platelets that promote cell proliferation and neovascularization [161]. NETs are also a prognostic indicator of venous thromboembolism: 
breast cancer patients present an increased risk (3-4 times) of venous thromboembolism, also associated with lower survival benefit [162], and high plasma levels of citrullinated histone $\mathrm{H} 3$, a biomarker of NET formation, are predictive of relapse in several cancers including breast types [161].

\section{Conclusions}

Heterogeneity in breast carcinomas can be appreciated at various levels, from morphology to molecular alterations, and there are well-known genotypic-phenotypic correlations. The TME also shows a multifaceted nature stemming from the different actors populating the intratumoral and the peritumoral stroma of breast carcinomas, and this has been acknowledged in the latest WHO classification of breast cancer. TNBCs and HER2-positive carcinomas are more immune-enriched ("hot tumors") compared to largely immune desert ("cold tumors") luminal carcinomas. TILs represent a strong indicator of good prognosis in TNBCs, and preliminary data are emerging suggesting de-escalation of therapy based on this biomarker. Nevertheless, a high level of TILs does not necessarily correlate with response to immune therapies. The IMPassion 130 phase III study in metastatic breast cancer patients has shown that PD-L1 expression observed in immune cells (including lymphocytes, macrophages, neutrophils, dendritic cells) is predictive of response to the combination therapy of atezolizumab plus nab-paclitaxel. At present, for patients with PD-L1 immune cell-positive metastatic TNBC, atezolizumab plus nab-paclitaxel is an important therapeutic option in a disease with high unmet needs. It should be acknowledged, however, that PD-L1 quantification represents a measurement of only one of the many potential mechanisms of immune evasion used by tumor cells. Moreover, the role of PD-L1 expression is yet to be fully elucidated, as the available data on early breast cancer from the phase
III neoadjuvant KEYNOTE522 study show a higher number of $\mathrm{pCR}$ rates in the pembrolizumab arm, regardless of the presence of PD-L1 expression. In this context, methods of quantification and scoring systems may also impact, and pathologists seem to have a central role in guiding the precise biomarker evaluation. Finally, there is evidence to support an important role played by other components of the microenvironment; nevertheless, these features are yet to be incorporated in diagnostic algorithms.

\section{Disclosure Statement}

C.M. has received personal/consultancy fees from Axiom Healthcare Strategies, Daiichi-Sankyo, MSD, Roche, Bayer, Thesaro, COR2ED. All of the other authors have no potential conflicts of interest to disclose.

\section{Funding Sources}

The authors are supported by the Italian Ministry of Education, University and Research - MIUR ("Dipartimenti di Eccellenza 2018-2022", project No. D15D18000410001, to the Department of Medical Sciences of the University of Turin, MIUR ex-60\% - 2019 and PRIN 2015HAJH8E to C.M.). C.M. has also received funding from AIRC under IG 2019 - ID 22850 project - P.I. Marchiò Caterina. L.A. is funded by the Fondazione Umberto Veronesi (PostDoctoral Fellowships 2018 and 2019). E.B. is the recipient of a $\mathrm{PhD}$ fellowship under the funding of "Dipartimenti di Eccellenza 20182022" (project No. D15D18000410001).

The funders had no role in data collection and analysis, or preparation of the manuscript.

\section{Author Contributions}

E. Cascardi, L.A., E.B., E.V., I.S., E. Chmielik, A.S. and C.M. performed the review of the literature. C.M. supervised the organization of the manuscript. L.A., E. Cascardi, E.B. and C.M. conceived the first draft of the manuscript, which was then reviewed and approved by all of the authors.

\section{References}

1 Lokuhetty D, White V, Watanabe R, Cree I. WHO classification of breast tumours. 5th ed. Geneva: WHO; 2019. Vol 2.

2 Nakagawa S, Miki Y, Miyashita M, Hata S, Takahashi Y, Rai Y, et al. Tumor microenvironment in invasive lobular carcinoma: possible therapeutic targets. Breast Cancer Res Treat. 2016 Jan;155(1):65-75.
3 Denkert C, von Minckwitz G, Darb-Esfahani S, Lederer B, Heppner BI, Weber KE, et al. Tumour-infiltrating lymphocytes and prognosis in different subtypes of breast cancer: a pooled analysis of 3771 patients treated with neoadjuvant therapy. Lancet Oncol. 2018 Jan; 19(1):40-50.
4 Marchiò C, Geyer F, Reis-Filho JS. Pathology and molecular pathology of breast cancer. In: Loda M, Mucci L, Mittelstadt ML, Van Hemelrijck M, Cotter MB, editors. Pathology and epidemiology of cancer. Basel: Springer International; 2016. p. 173-231.

5 Dias AS, Almeida CR, Helguero LA, Duarte IF. Metabolic crosstalk in the breast cancer microenvironment. Eur J Cancer. 2019 Nov; 121:154-71. 
6 Wang M, Zhang C, Song Y, Wang Z, Wang Y, Luo F, et al. Mechanism of immune evasion in breast cancer. OncoTargets Ther. 2017 Mar;10:1561-73.

7 Gatti-Mays ME, Balko JM, Gameiro SR, Bear HD, Prabhakaran S, Fukui J, et al. If we build it they will come: targeting the immune response to breast cancer. NPJ Breast Cancer. 2019 Oct;5(1):37.

8 Salgado R, Denkert C, Demaria S, Sirtaine N, Klauschen F, Pruneri G, et al.; International TILs Working Group 2014. The evaluation of tumor-infiltrating lymphocytes (TILs) in breast cancer: recommendations by an International TILs Working Group 2014. Ann Oncol. 2015 Feb;26(2):259-71.

9 International Immuno-Oncology Biomarker Working Group on Breast Cancer [Internet]. Available from: https://www.tilsinbreastcancer.org/

10 Stanton SE, Adams S, Disis ML. Variation in the Incidence and Magnitude of Tumor-Infiltrating Lymphocytes in Breast Cancer Subtypes: A Systematic Review. JAMA Oncol. 2016 Oct;2(10):1354-60.

11 Wein L, Savas P, Luen SJ, Virassamy B, Salgado R, Loi S. Clinical validity and utility of tumor-infiltrating lymphocytes in routine clinical practice for breast cancer patients: current and future directions. Front Oncol. 2017 Aug;7:156.

12 Loi S, Sirtaine N, Piette F, Salgado R, Viale G, Van Eenoo F, et al. Prognostic and predictive value of tumor-infiltrating lymphocytes in a phase III randomized adjuvant breast cancer trial in node-positive breast cancer comparing the addition of docetaxel to doxorubicin with doxorubicin-based chemotherapy: BIG 02-98. J Clin Oncol. 2013 Mar;31(7):860-7.

13 Ali HR, Provenzano E, Dawson SJ, Blows FM, Liu B, Shah M, et al. Association between CD8+ T-cell infiltration and breast cancer survival in 12,439 patients. Ann Oncol. 2014 Aug;25(8):1536-43.

14 Hamy AS, Bonsang-Kitzis H, De Croze D, Laas E, Darrigues L, Topciu L, et al. Interaction between Molecular Subtypes and Stromal Immune Infiltration before and after Treatment in Breast Cancer Patients Treated with Neoadjuvant Chemotherapy. Clin Cancer Res. 2019 Nov;25(22):6731-41.

15 Dieci MV, Mathieu MC, Guarneri V, Conte P, Delaloge S, Andre F, et al. Prognostic and predictive value of tumor-infiltrating lymphocytes in two phase III randomized adjuvant breast cancer trials. Ann Oncol. 2015 Aug; 26(8):1698-704.

16 Loi S, Michiels S, Salgado R, Sirtaine N, Jose $\mathrm{V}$, Fumagalli D, et al. Tumor infiltrating lymphocytes are prognostic in triple negative breast cancer and predictive for trastuzumab benefit in early breast cancer: results from the FinHER trial. Ann Oncol. 2014 Aug;25(8): 1544-50.
17 Adams S, Gray RJ, Demaria S, Goldstein L, Perez EA, Shulman LN, et al. Prognostic value of tumor-infiltrating lymphocytes in triplenegative breast cancers from two phase III randomized adjuvant breast cancer trials: ECOG 2197 and ECOG 1199. J Clin Oncol. 2014 Sep;32(27):2959-66.

18 Denkert C, Loibl S, Noske A, Roller M, Müller BM, Komor M, et al. Tumor-associated lymphocytes as an independent predictor of response to neoadjuvant chemotherapy in breast cancer. J Clin Oncol. 2010 Jan;28(1): 105-13.

19 Denkert C, von Minckwitz G, Brase JC, Sinn BV, Gade S, Kronenwett R, et al. Tumor-infiltrating lymphocytes and response to neoadjuvant chemotherapy with or without carboplatin in human epidermal growth factor receptor 2-positive and triple-negative primary breast cancers. J Clin Oncol. 2015 Mar;33(9): 983-91.

20 Salgado R, Denkert C, Campbell C, Savas P, Nuciforo P, Aura C, et al. Tumor-infiltrating lymphocytes and associations with pathological complete response and event-free survival in HER2-positive early-stage breast cancer treated with lapatinib and trastuzumab: a secondary analysis of the NeoALTTO trial. JAMA Oncol. 2015 Jul;1(4):448-54.

21 Park JH, Jonas SF, Bataillon G, Criscitiello C, Salgado R, Loi S, et al. Prognostic value of tumor-infiltrating lymphocytes in patients with early-stage triple-negative breast cancers (TNBC) who did not receive adjuvant chemotherapy. Ann Oncol. 2019 Dec;30(12): 1941-9.

22 Dieci M, Conte P, Bisagni G. Association of tumor-infiltrating lymphocytes with metastasis-free survival for patients with early HER $2+$ breast cancer treated with adjuvant chemotherapy and trastuzumab: results from the randomized ShortHER trial. European Society of Medical Oncology 2018 Congress. 1923 October 2018, Munich, Germany.

23 Perez EA, Ballman KV, Tenner KS, Thompson EA, Badve SS, Bailey H, et al. Association of Stromal Tumor-Infiltrating Lymphocytes With Recurrence-Free Survival in the N9831 Adjuvant Trial in Patients With Early-Stage HER2-Positive Breast Cancer. JAMA Oncol. 2016 Jan;2(1):56-64.

24 Swisher SK, Wu Y, Castaneda CA, Lyons GR, Yang F, Tapia C, et al. Interobserver Agreement Between Pathologists Assessing Tumor-Infiltrating Lymphocytes (TILs) in Breast Cancer Using Methodology Proposed by the International TILs Working Group. Ann Surg Oncol. 2016 Jul;23(7):2242-8.

25 Denkert C, Wienert S, Poterie A, Loibl S, Budczies J, Badve S, et al. Standardized evaluation of tumor-infiltrating lymphocytes in breast cancer: results of the ring studies of the international immuno-oncology biomarker working group. Mod Pathol. 2016 Oct;29(10): 1155-64.
26 Tramm T, Di Caterino T, Jylling AB, Lelkaitis G, Lænkholm AV, Ragó P, et al.; Scientific Committee of Pathology, Danish Breast Cancer Group (DBCG). Standardized assessment of tumor-infiltrating lymphocytes in breast cancer: an evaluation of inter-observer agreement between pathologists. Acta Oncol. 2018 Jan;57(1):90-4.

27 Althobiti M, Aleskandarany MA, Joseph C, Toss M, Mongan N, Diez-Rodriguez M, et al. Heterogeneity of tumour-infiltrating lymphocytes in breast cancer and its prognostic significance. Histopathology. 2018 Dec;73(6): 887-96.

28 Gu-Trantien C, Loi S, Garaud S, Equeter C, Libin $\mathrm{M}$, de Wind $\mathrm{A}$, et al. $\mathrm{CD}^{+}$follicular helper $\mathrm{T}$ cell infiltration predicts breast cancer survival. J Clin Invest. 2013 Jul;123(7):287392.

29 Su S, Liao J, Liu J, Huang D, He C, Chen F, et al. Blocking the recruitment of naive $\mathrm{CD} 4+\mathrm{T}$ cells reverses immunosuppression in breast cancer. Cell Res. 2017 Apr;27(4):461-82.

30 Bense RD, Sotiriou C, Piccart-Gebhart MJ, Haanen JB, van Vugt MA, de Vries EG, et al. Relevance of Tumor-Infiltrating Immune Cell Composition and Functionality for Disease Outcome in Breast Cancer. J Natl Cancer Inst. 2016 Oct;109(1):djw192.

31 Burugu S, Asleh-Aburaya K, Nielsen TO. Immune infiltrates in the breast cancer microenvironment: detection, characterization and clinical implication. Breast Cancer. 2017 Jan; 24(1):3-15.

32 Luckheeram RV, Zhou R, Verma AD, Xia B. CD4+ T cells: differentiation and functions. Clin Dev Immunol. 2012;2012:925135.

33 Fridman WH, Pagès F, Sautès-Fridman C, Galon J. The immune contexture in human tumours: impact on clinical outcome. Nat Rev Cancer. 2012 Mar;12(4):298-306.

34 Gonzalez H, Hagerling C, Werb Z. Roles of the immune system in cancer: from tumor initiation to metastatic progression. Genes Dev. 2018 Oct;32(19-20):1267-84.

35 Tamma R, Annese T, Ruggieri S, Brunetti O, Longo V, Cascardi E, et al. Inflammatory cells infiltrate and angiogenesis in locally advanced and metastatic cholangiocarcinoma. Eur J Clin Invest. 2019 May;49(5):e13087.

36 Gupta S, Joshi K, Wig JD, Arora SK. Intratumoral FOXP3 expression in infiltrating breast carcinoma: its association with clinicopathologic parameters and angiogenesis. Acta Oncol. 2007;46(6):792-7.

37 Allaoui R, Hagerling C, Desmond E, Warfvinge CF, Jirström K, Leandersson K. Infiltration of $\gamma-\delta$ T cells, IL-17+ T cells and FoxP3+ T cells in human breast cancer. Cancer Biomark. 2017 Dec;20(4):395-409.

38 Shou J, Zhang Z, Lai Y, Chen Z, Huang J. Worse outcome in breast cancer with higher tumor-infiltrating FOXP3+ Tregs : a systematic review and meta-analysis. BMC Cancer. 2016 Aug;16(1):687. 
39 Bos PD, Plitas G, Rudra D, Lee SY, Rudensky AY. Transient regulatory $T$ cell ablation deters oncogene-driven breast cancer and enhances radiotherapy. J Exp Med. 2013 Oct; 210(11):2435-66.

40 Metelli A, Wu BX, Fugle CW, Rachidi S, Sun $S$, Zhang Y, et al. Surface Expression of TGF $\beta$ Docking Receptor GARP Promotes Oncogenesis and Immune Tolerance in Breast Cancer. Cancer Res. 2016 Dec;76(24):710617.

41 Hoffman W, Lakkis FG, Chalasani G. B Cells, Antibodies, and More. Clin J Am Soc Nephrol. 2016 Jan;11(1):137-54.

42 Pylayeva-Gupta Y, Das S, Handler JS, Hajdu $\mathrm{CH}$, Coffre M, Koralov SB, et al. IL35-Producing B Cells Promote the Development of Pancreatic Neoplasia. Cancer Discov. 2016 Mar; 6(3):247-55.

43 Woo JR, Liss MA, Muldong MT, Palazzi K, Strasner A, Ammirante M, et al. Tumor infiltrating B-cells are increased in prostate cancer tissue. J Transl Med. 2014 Jan;12(1):30.

44 Hussein MR, Hassan HI. Analysis of the mononuclear inflammatory cell infiltrate in the normal breast, benign proliferative breast disease, in situ and infiltrating ductal breast carcinomas: preliminary observations. J Clin Pathol. 2006 Sep;59(9):972-7.

45 Coronella-Wood JA, Hersh EM. Naturally occurring B-cell responses to breast cancer. Cancer Immunol Immunother. 2003 Dec; 52(12):715-38

46 Chin Y, Janseens J, Vandepitte J, Vandenbrande J, Opdebeek L, Raus J. Phenotypic analysis of tumor-infiltrating lymphocytes from human breast cancer. Anticancer Res. 1992 Sep-Oct;12(5):1463-6.

47 Marsigliante S, Biscozzo L, Marra A, Nicolardi G, Leo G, Lobreglio GB, et al. Computerised counting of tumour infiltrating lymphocytes in 90 breast cancer specimens. Cancer Lett. 1999 May;139(1):33-41.

48 Nelson BH. CD20+ B cells: the other tumorinfiltrating lymphocytes. J Immunol. 2010 Nov; 185(9):4977-82.

49 Coronella JA, Spier C, Welch M, Trevor KT, Stopeck AT, Villar H, et al. Antigen-driven oligoclonal expansion of tumor-infiltrating $B$ cells in infiltrating ductal carcinoma of the breast. J Immunol. 2002 Aug;169(4):1829-36.

50 Yakirevich E, Izhak OB, Rennert G, Kovacs ZG, Resnick MB. Cytotoxic phenotype of tumor infiltrating lymphocytes in medullary carcinoma of the breast. Mod Pathol. 1999 Nov;12(11):1050-6.

51 Tamiolakis D, Simopoulos C, Cheva A, Lambropoulou M, Kotini A, Jivannakis T, et al. Immunophenotypic profile of tumor infiltrating lymphocytes in medullary carcinoma of the breast. Eur J Gynaecol Oncol. 2002; 23(5):433-6.

52 Ridolfi RL, Rosen PP, Port A, Kinne D, Miké V. Medullary carcinoma of the breast: a clinicopathologic study with 10 year follow-up. Cancer. 1977 Oct;40(4):1365-85.
53 Lim KH, Telisinghe PU, Abdullah MS, Ramasamy R. Possible significance of differences in proportions of cytotoxic $\mathrm{T}$ cells and $\mathrm{B}$-lineage cells in the tumour-infiltrating lymphocytes of typical and atypical medullary carcinomas of the breast. Cancer Immun. 2010 Jan; 10:3.

54 Mao Y, Qu Q, Chen X, Huang O, Wu J, Shen K. The Prognostic Value of Tumor-Infiltrating Lymphocytes in Breast Cancer: A Systematic Review and Meta-Analysis. PLoS One. 2016 Apr;11(4):e0152500.

55 Hsu SM, Raine L, Nayak RN. Medullary carcinoma of breast: an immunohistochemical study of its lymphoid stroma. Cancer. 1981 Sep;48(6):1368-76.

56 Yeong J, Lim JC, Lee B, Li H, Chia N, Ong CC, et al. High densities of tumor-associated plasma cells predict improved prognosis in triple negative breast cancer. Front Immunol. 2018 May;9:1209.

57 Turkewitz D, Bastian C. Infant and child nutrition. Controversies and recommendations. Postgrad Med. 1986;79(2):151-4, 9-64.

58 Angus L, Smid M, Wilting SM, van Riet J, Van Hoeck A, Nguyen L, et al. The genomic landscape of metastatic breast cancer highlights changes in mutation and signature frequencies. Nat Genet. 2019 Oct;51(10):1450-8.

59 Fancello L, Gandini S, Pelicci PG, Mazzarella L. Tumor mutational burden quantification from targeted gene panels: major advancements and challenges. J Immunother Cancer. 2019 Jul;7(1):183.

60 Samstein RM, Lee CH, Shoushtari AN, Hellmann MD, Shen R, Janjigian YY, et al. Tumor mutational load predicts survival after immunotherapy across multiple cancer types. Nat Genet. 2019 Feb;51(2):202-6.

61 Rooney MS, Shukla SA, Wu CJ, Getz G, Hacohen N. Molecular and genetic properties of tumors associated with local immune cytolytic activity. Cell. 2015 Jan;160(1-2):48-61.

62 Cristescu R, Mogg R, Ayers M, Albright A, Murphy E, Yearley J, et al. Pan-tumor genomic biomarkers for PD-1 checkpoint blockadebased immunotherapy. Science. 2018 Oct; 362(6411):eaar3593.

63 Spranger S, Luke JJ, Bao R, Zha Y, Hernandez KM, Li Y, et al. Density of immunogenic antigens does not explain the presence or absence of the T-cell-inflamed tumor microenvironment in melanoma. Proc Natl Acad Sci USA. 2016 Nov;113(48):E7759-68.

64 Luen S, Virassamy B, Savas P, Salgado R, Loi $S$. The genomic landscape of breast cancer and its interaction with host immunity. Breast. 2016 Oct;29:241-50.

65 Karn T, Jiang T, Hatzis C, Sänger N, El-Balat A, Rody A, et al. Association Between Genomic Metrics and Immune Infiltration in Triple-Negative Breast Cancer. JAMA Oncol. 2017 Dec;3(12):1707-11.

66 Safonov A, Jiang T, Bianchini G, Győrffy B, Karn T, Hatzis C, et al. Immune Gene Expression Is Associated with Genomic Aberrations in Breast Cancer. Cancer Res. 2017 Jun; 77(12):3317-24.
67 Thomas A, Routh ED, Pullikuth A, Jin G, Su J, Chou JW, et al. Tumor mutational burden is a determinant of immune-mediated survival in breast cancer. OncoImmunology. 2018 Jul;7(10):e1490854.

68 Kaplan DH, Shankaran V, Dighe AS, Stockert E, Aguet M, Old LJ, et al. Demonstration of an interferon gamma-dependent tumor surveillance system in immunocompetent mice. Proc Natl Acad Sci USA. 1998 Jun;95(13): 7556-61.

69 Roberti MP, Mordoh J, Levy EM. Biological role of NK cells and immunotherapeutic approaches in breast cancer. Front Immunol. 2012 Dec;3:375.

70 Mamessier E, Sylvain A, Bertucci F, Castellano R, Finetti P, Houvenaeghel G, et al. Human breast tumor cells induce self-tolerance mechanisms to avoid NKG2D-mediated and DNAM-mediated NK cell recognition. Cancer Res. 2011 Nov;71(21):6621-32.

71 Desmedt C, Piette F, Loi S, Wang Y, Lallemand F, Haibe-Kains B, et al.; TRANSBIG Consortium. Strong time dependence of the 76-gene prognostic signature for node-negative breast cancer patients in the TRANSBIG multicenter independent validation series. Clin Cancer Res. 2007 Jun;13(11):3207-14.

72 Miller LD, Smeds J, George J, Vega VB, Vergara L, Ploner A, et al. An expression signature for p53 status in human breast cancer predicts mutation status, transcriptional effects, and patient survival. Proc Natl Acad Sci USA. 2005 Sep;102(38):13550-5.

73 Verma C, Kaewkangsadan V, Eremin JM, Cowley GP, Ilyas M, El-Sheemy MA, et al. Natural killer (NK) cell profiles in blood and tumour in women with large and locally advanced breast cancer (LLABC) and their contribution to a pathological complete response (PCR) in the tumour following neoadjuvant chemotherapy (NAC): differential restoration of blood profiles by NAC and surgery. J Transl Med. 2015 Jun;13(1):180.

74 Muntasell A, Rojo F, Servitja S, Rubio-Perez C, Cabo M, Tamborero D, et al. NK Cell Infiltrates and HLA Class I Expression in Primary HER2+ Breast Cancer Predict and Uncouple Pathological Response and Disease-free Survival. Clin Cancer Res. 2019 Mar;25(5):153545.

75 Garcia-Chagollan M, Carranza-Torres IE, Carranza-Rosales P, Guzmán-Delgado NE, Ramírez-Montoya $\mathrm{H}$, Martínez-Silva MG, et al. Expression of NK cell surface receptors in breast cancer tissue as predictors of resistance to antineoplastic treatment. Technol Cancer Res Treat. 2018 Jan;17:1533033818764499.

76 Ascierto ML, Idowu MO, Zhao Y, Khalak H, Payne KK, Wang XY, et al. Molecular signatures mostly associated with NK cells are predictive of relapse free survival in breast cancer patients. J Transl Med. 2013 Jun;11(1):145. 
77 Mamessier E, Sylvain A, Thibult ML, Houvenaeghel G, Jacquemier J, Castellano R, et al. Human breast cancer cells enhance self tolerance by promoting evasion from NK cell antitumor immunity. J Clin Invest. 2011 Sep; 121(9):3609-22.

78 Cifaldi L, Locatelli F, Marasco E, Moretta L, Pistoia V. Boosting Natural Killer Cell-Based Immunotherapy with Anticancer Drugs: a Perspective. Trends Mol Med. 2017 Dec; 23(12):1156-75.

79 Baragaño Raneros A, Martín-Palanco V, Fernandez AF, Rodriguez RM, Fraga MF, LopezLarrea C, et al. Methylation of NKG2D ligands contributes to immune system evasion in acute myeloid leukemia. Genes Immun. 2015 Jan-Feb;16(1):71-82.

80 Coudert JD, Zimmer J, Tomasello E, Cebecauer M, Colonna M, Vivier E, et al. Altered NKG2D function in NK cells induced by chronic exposure to NKG2D ligand-expressing tumor cells. Blood. 2005 Sep;106(5): $1711-7$.

81 Obeid E, Nanda R, Fu YX, Olopade OI. The role of tumor-associated macrophages in breast cancer progression (review) [review]. Int J Oncol. 2013 Jul;43(1):5-12.

82 Sica A, Larghi P, Mancino A, Rubino L, Porta C, Totaro MG, et al. Macrophage polarization in tumour progression. Semin Cancer Biol. 2008 Oct;18(5):349-55.

83 Chen JJ, Lin YC, Yao PL, Yuan A, Chen HY, Shun CT, et al. Tumor-associated macrophages: the double-edged sword in cancer progression. J Clin Oncol. 2005 Feb;23(5): 953-64.

84 Williams CB, Yeh ES, Soloff AC. Tumor-associated macrophages: unwitting accomplices in breast cancer malignancy. NPJ Breast Cancer. 2016;2(1):2.

85 Xu M, Liu M, Du X, Li S, Li H, Li X, et al. Intratumoral Delivery of IL-21 Overcomes Anti-Her2/Neu Resistance through Shifting Tumor-Associated Macrophages from M2 to M1 Phenotype. J Immunol. 2015 May; 194(10):4997-5006.

86 Genin M, Clement F, Fattaccioli A, Raes M, Michiels C. M1 and M2 macrophages derived from THP-1 cells differentially modulate the response of cancer cells to etoposide. BMC Cancer. 2015 Aug;15(1):577.

87 Veremeyko T, Siddiqui S, Sotnikov I, Yung A, Ponomarev ED. IL-4/IL-13-dependent and independent expression of miR-124 and its contribution to M2 phenotype of monocytic cells in normal conditions and during allergic inflammation. PLoS One. 2013 Dec; 8(12):e81774.

88 Lesterhuis WJ, Punt CJ, Hato SV, EleveldTrancikova D, Jansen BJ, Nierkens S, et al. Platinum-based drugs disrupt STAT6-mediated suppression of immune responses against cancer in humans and mice. J Clin Invest. 2011 Aug;121(8):3100-8.
89 Cannarile MA, Weisser M, Jacob W, Jegg $\mathrm{AM}$, Ries $\mathrm{CH}$, Rüttinger D. Colony-stimulating factor 1 receptor (CSF1R) inhibitors in cancer therapy. J Immunother Cancer. 2017 Jul;5(1):53.

90 Hanna A, Metge BJ, Bailey SK, Chen D, Chandrashekar DS, Varambally S, et al. Inhibition of Hedgehog signaling reprograms the dysfunctional immune microenvironment in breast cancer. OncoImmunology. 2018 Dec;8(3): 1548241

91 Roh-Johnson M, Bravo-Cordero JJ, Patsialou A, Sharma VP, Guo P, Liu H, et al. Macrophage contact induces RhoA GTPase signaling to trigger tumor cell intravasation. Oncogene. 2014 Aug;33(33):4203-12.

92 Goswami S, Sahai E, Wyckoff JB, Cammer $\mathrm{M}$, Cox D, Pixley FJ, et al. Macrophages promote the invasion of breast carcinoma cells via a colony-stimulating factor-1/epidermal growth factor paracrine loop. Cancer Res. 2005 Jun;65(12):5278-83.

93 Bonapace L, Coissieux MM, Wyckoff J, Mertz KD, Varga Z, Junt T, et al. Cessation of CCL2 inhibition accelerates breast cancer metastasis by promoting angiogenesis. $\mathrm{Na}-$ ture. 2014 Nov;515(7525):130-3.

$94 \mathrm{Lu} \mathrm{X}$, Kang Y. Chemokine (C-C motif) ligand 2 engages CCR2+ stromal cells of monocytic origin to promote breast cancer metastasis to lung and bone. J Biol Chem. 2009 Oct;284(42):29087-96.

95 Qian BZ, Zhang H, Li J, He T, Yeo EJ, Soong $\mathrm{DY}$, et al. FLT1 signaling in metastasis-associated macrophages activates an inflammatory signature that promotes breast cancer metastasis. J Exp Med. 2015 Aug;212(9): 1433-48.

96 Kessenbrock K, Plaks V, Werb Z. Matrix metalloproteinases: regulators of the tumor microenvironment. Cell. 2010 Apr;141(1): 52-67.

97 Sousa S, Brion R, Lintunen M, Kronqvist P, Sandholm J, Mönkkönen J, et al. Human breast cancer cells educate macrophages toward the M2 activation status. Breast Cancer Res. 2015 Aug;17(1):101.

98 Leek RD, Lewis CE, Whitehouse R, Greenall M, Clarke J, Harris AL. Association of macrophage infiltration with angiogenesis and prognosis in invasive breast carcinoma. Cancer Res. 1996 Oct;56(20):4625-9.

99 Campbell MJ, Tonlaar NY, Garwood ER, Huo D, Moore DH, Khramtsov AI, et al. Proliferating macrophages associated with high grade, hormone receptor negative breast cancer and poor clinical outcome. Breast Cancer Res Treat. 2011 Aug;128(3): 703-11.

100 Junankar S, Shay G, Jurczyluk J, Ali N, Down J, Pocock N, et al. Real-time intravital imaging establishes tumor-associated macrophages as the extraskeletal target of bisphosphonate action in cancer. Cancer Discov. 2015 Jan;5(1):35-42.
101 Diel IJ, Solomayer EF, Costa SD, Gollan C, Goerner R, Wallwiener D, et al. Reduction in new metastases in breast cancer with adjuvant clodronate treatment. N Engl J Med. 1998 Aug;339(6):357-63.

102 Spaan AN, Surewaard BG, Nijland R, van Strijp JA. Neutrophils versus Staphylococcus aureus: a biological tug of war. Annu Rey Microbiol. 2013;67(1):629-50.

103 Brinkmann V, Reichard U, Goosmann C, Fauler B, Uhlemann Y, Weiss DS, et al. Neutrophil extracellular traps kill bacteria. Science. 2004 Mar;303(5663):1532-5.

104 Treffers LW, Hiemstra IH, Kuijpers TW, van den Berg TK, Matlung HL. Neutrophils in cancer. Immunol Rev. 2016 Sep;273(1): $312-28$.

105 Fridlender ZG, Sun J, Kim S, Kapoor V, Cheng G, Ling L, et al. Polarization of tumor-associated neutrophil phenotype by TGF-beta: "N1" versus "N2" TAN. Cancer Cell. 2009 Sep;16(3):183-94.

106 Albrengues J, Shields MA, Ng D, Park CG, Ambrico A, Poindexter ME, et al. Neutrophil extracellular traps produced during inflammation awaken dormant cancer cells in mice. Science.2018 Sep;361(6409):eaao4227.

107 Queen MM, Ryan RE, Holzer RG, KellerPeck CR, Jorcyk CL. Breast cancer cells stimulate neutrophils to produce oncostatin M: potential implications for tumor progression. Cancer Res. 2005 Oct;65(19):8896904.

108 Szczerba BM, Castro-Giner F, Vetter M, Krol I, Gkountela S, Landin J, et al. Neutrophils escort circulating tumour cells to enable cell cycle progression. Nature. 2019 Feb; 566(7745):553-7.

109 Egeblad M, de Visser KE. Sticking together helps cancer to spread. Nature. 2019 Feb; 566(7745):459-60.

110 Coffelt SB, Kersten K, Doornebal CW, Weiden J, Vrijland K, Hau CS, et al. IL-17-producing $\gamma \delta$ T cells and neutrophils conspire to promote breast cancer metastasis. Nature. 2015 Jun;522(7556):345-8.

111 Cools-Lartigue J, Spicer J, McDonald B, Gowing S, Chow S, Giannias B, et al. Neutrophil extracellular traps sequester circulating tumor cells and promote metastasis. J Clin Invest. 2013 Jul;123(8):67484.

112 Iwase T, Sangai T, Sakakibara M, Sakakibara J, Ishigami E, Hayama S, et al. An increased neutrophil-to-lymphocyte ratio predicts poorer survival following recurrence for patients with breast cancer. Mol Clin Oncol. 2017 Feb;6(2):266-70.

113 Ethier JL, Desautels D, Templeton A, Shah PS, Amir E. Prognostic role of neutrophilto-lymphocyte ratio in breast cancer: a systematic review and meta-analysis. Breast Cancer Res. 2017 Jan;19(1):2.

Annaratone/Cascardi/Vissio/Sarotto/ Chmielik/Sapino/Berrino/Marchiò 
114 Duan J, Pan L, Yang M. Preoperative elevated neutrophil-to-lymphocyte ratio (NLR) and derived NLR are associated with poor prognosis in patients with breast cancer: A meta-analysis. Medicine (Baltimore). 2018 Dec;97(49):e13340.

115 Ferroni P, Roselli M, Buonomo OC, Spila A, Portarena I, Laudisi A, et al. Prognostic Significance of Neutrophil-to-lymphocyte Ratio in the Framework of the 8th TNM Edition for Breast Cancer. Anticancer Res. 2018 Aug;38(8):4705-12.

116 Chen Y, Chen K, Xiao X, Nie Y, Qu S, Gong $\mathrm{C}$, et al. Pretreatment neutrophil-to-lymphocyte ratio is correlated with response to neoadjuvant chemotherapy as an independent prognostic indicator in breast cancer patients: a retrospective study. BMC Cancer. 2016 May; 16(1):320.

117 Blackley EF, Loi S. Targeting immune pathways in breast cancer: review of the prognostic utility of TILs in early stage triple negative breast cancer (TNBC). Breast. 2019 Nov;48 Suppl 1:S44-8.

118 Schmid P, Adams S, Rugo HS, Schneeweiss $\mathrm{A}$, Barrios $\mathrm{CH}$, Iwata $\mathrm{H}$, et al; IMpassion 130 Trial Investigators. Atezolizumab and nabpaclitaxel in advanced triple-negative breast cancer. N Engl J Med. 2018 Nov;379(22): 2108-21.

119 Genentech. Tecentriq (atezolizumab): package insert [cited 2019 Nov 5]. Available from: https://www.gene.com/download/pdf/ tecentriq_prescribing.pdf

120 Roche. Tecentriq (atezolizumab): summary of product characteristics. Available from: https://www.ema.europa.eu/en/documents/ product-information/tecentriq-epar-product-information_en.pdf

121 Schmid P, Cruz C, Braiteh FS, Eder JP, Tolaney S, Kuter I, et al. Atezolizumab in metastatic TNBC (mTNBC): long-term clinical outcomes and biomarker analyses [abstract]. Cancer Res. 2019;77:abstract No 2986.

122 Rugo HS, Loi S, Adams S, Schmid P, Schneeweiss $\mathrm{AH}$, Barrios $\mathrm{CH}$, et al. Performance of PD-L1 immunohistochemistry (IHC) assays in unresectable locally advanced or metastatic triple-negative breast cancer (mTNBC): post-hoc analysis of IMpassion130. Ann Oncol. 2019 Oct;2019(30):v858-9.

123 Schmid P, Cortes J, Pusztai L, McArthur H, Kümmel S, Bergh J, et al; KEYNOTE-522 Investigators. Pembrolizumab for early triplenegative breast cancer. N Engl J Med. 2020 Feb;382(9):810-21.

124 Gascard P, Tlsty TD. Carcinoma-associated fibroblasts: orchestrating the composition of malignancy. Genes Dev. 2016 May;30(9): 1002-19.

125 Brabletz T, Lyden D, Steeg PS, Werb Z. Roadblocks to translational advances on metastasis research. Nat Med. 2013 Sep; 19(9):1104-9.
$126 \mathrm{Hu} \mathrm{G}$, Xu F, Zhong K, Wang S, Huang L, Chen W. Activated Tumor-infiltrating Fibroblasts Predict Worse Prognosis in Breast Cancer Patients. J Cancer. 2018 Sep;9(20): 3736-42.

127 Kuczek DE, Larsen AM, Thorseth ML, Carretta M, Kalvisa A, Siersbæk MS, et al. Collagen density regulates the activity of tumorinfiltrating T cells. J Immunother Cancer. 2019 Mar;7(1):68.

128 Dumont N, Liu B, Defilippis RA, Chang H, Rabban JT, Karnezis AN, et al. Breast fibroblasts modulate early dissemination, tumorigenesis, and metastasis through alteration of extracellular matrix characteristics. Neoplasia. 2013 Mar;15(3):249-62.

129 Cazet AS, Hui MN, Elsworth BL, Wu SZ, Roden D, Chan CL, et al. Targeting stromal remodeling and cancer stem cell plasticity overcomes chemoresistance in triple negative breast cancer. Nat Commun. 2018 Jul; 9(1):2897.

130 Costa A, Kieffer Y, Scholer-Dahirel A, Pelon F, Bourachot B, Cardon M, et al. Fibroblast heterogeneity and immunosuppressive environment in human breast cancer. Cancer Cell. 2018;33(3):463-79. e10.

131 Lee J, Hong BS, Ryu HS, Lee HB, Lee M, Park IA, et al. Transition into inflammatory cancer-associated adipocytes in breast cancer microenvironment requires microRNA regulatory mechanism. PLoS One. 2017 Mar; 12(3): $\mathrm{e} 0174126$.

132 Wu Q, Li B, Li Z, Li J, Sun S, Sun S. Cancerassociated adipocytes: key players in breast cancer progression. J Hematol Oncol. 2019 Sep;12(1):95.

133 Choi J, Cha YJ, Koo JS. Adipocyte biology in breast cancer: from silent bystander to active facilitator. Prog Lipid Res. 2018 Jan;69:1120.

134 Elliott BE, Tam SP, Dexter D, Chen ZQ. Capacity of adipose tissue to promote growth and metastasis of a murine mammary carcinoma: effect of estrogen and progesterone. Int J Cancer. 1992 May;51(3):416-24.

135 He JY, Wei XH, Li SJ, Liu Y, Hu HL, Li ZZ, et al. Adipocyte-derived IL- 6 and leptin promote breast Cancer metastasis via upregulation of Lysyl Hydroxylase-2 expression. Cell Commun Signal. 2018 Dec;16(1):100.

136 Dirat B, Bochet L, Dabek M, Daviaud D, Dauvillier S, Majed B, et al. Cancer-associated adipocytes exhibit an activated phenotype and contribute to breast cancer invasion. Cancer Res. 2011 Apr;71(7):2455-65.

137 Juárez-Cruz JC, Zuñiga-Eulogio MD, OleaFlores M, Castañeda-Saucedo E, MendozaCatalán MA, Ortuño-Pineda C, et al. Leptin induces cell migration and invasion in a FAK-Src-dependent manner in breast cancer cells. Endocr Connect. 2019 Nov;8(11): 1539-52.
138 Balaban S, Shearer RF, Lee LS, van Geldermalsen M, Schreuder M, Shtein HC, et al. Adipocyte lipolysis links obesity to breast cancer growth: adipocyte-derived fatty acids drive breast cancer cell proliferation and $\mathrm{mi}$ gration. Cancer Metab. 2017 Jan;5(1):1.

139 Sultana R, Kataki AC, Borthakur BB, Basumatary TK, Bose S. Imbalance in leptin-adiponectin levels and leptin receptor expression as chief contributors to triple negative breast cancer progression in Northeast India. Gene. 2017 Jul;621:51-8.

140 Kim HS, Jung M, Choi SK, Woo J, Piao YJ, Hwang EH, et al. IL-6-mediated cross-talk between human preadipocytes and ductal carcinoma in situ in breast cancer progression. J Exp Clin Cancer Res. 2018 Aug;37(1): 200.

141 Gyamfi J, Eom M, Koo JS, Choi J. Multifaceted Roles of Interleukin-6 in AdipocyteBreast Cancer Cell Interaction. Transl Oncol. 2018 Apr;11(2):275-85.

142 Wu B, Sun X, Gupta HB, Yuan B, Li J, Ge F, et al. Adipose PD-L1 Modulates PD-1/PDL1 Checkpoint Blockade Immunotherapy Efficacy in Breast Cancer. OncoImmunology. 2018 Aug;7(11):e1500107.

143 Bevilacqua P, Barbareschi M, Verderio P, Boracchi P, Caffo O, Dalla Palma P, et al. Prognostic value of intratumoral microvessel density, a measure of tumor angiogenesis, in node-negative breast carcinoma-results of a multiparametric study. Breast Cancer Res Treat. 1995;36(2):205-17.

144 Choi WW, Lewis MM, Lawson D, Yin-Goen Q, Birdsong GG, Cotsonis GA, et al. Angiogenic and lymphangiogenic microvessel density in breast carcinoma: correlation with clinicopathologic parameters and VEGF-family gene expression. Mod Pathol. 2005 Jan;18(1):143-52.

145 Obermair A, Kurz C, Czerwenka K, Thoma M, Kaider A, Wagner T, et al. Microvessel density and vessel invasion in lymph-nodenegative breast cancer: effect on recurrencefree survival. Int J Cancer. 1995 Jul;62(2): 126-31.

146 Relf M, LeJeune S, Scott PA, Fox S, Smith K, Leek R, et al. Expression of the angiogenic factors vascular endothelial cell growth factor, acidic and basic fibroblast growth factor, tumor growth factor beta-1, platelet-derived endothelial cell growth factor, placenta growth factor, and pleiotrophin in human primary breast cancer and its relation to angiogenesis. Cancer Res. 1997 Mar;57(5): 963-9.

147 Schneider BP, Miller KD. Angiogenesis of breast cancer. J Clin Oncol. 2005 Mar;23(8): 1782-90.

148 Gasparini G, Toi M, Gion M, Verderio P, Dittadi R, Hanatani M, et al. Prognostic significance of vascular endothelial growth factor protein in node-negative breast carcinoma. J Natl Cancer Inst. 1997 Jan;89(2):13947. 
149 Gasparini G, Toi M, Miceli R, Vermeulen PB, Dittadi R, Biganzoli E, et al. Clinical relevance of vascular endothelial growth factor and thymidine phosphorylase in patients with node-positive breast cancer treated with either adjuvant chemotherapy or hormone therapy. Cancer J Sci Am. 1999 MarApr;5(2):101-11.

150 Foekens JA, Peters HA, Grebenchtchikov N, Look MP, Meijer-van Gelder ME, GeurtsMoespot A, et al. High tumor levels of vascular endothelial growth factor predict poor response to systemic therapy in advanced breast cancer. Cancer Res. 2001 Jul;61(14): 5407-14.

151 Guo S, Colbert LS, Fuller M, Zhang Y, Gonzalez-Perez RR. Vascular endothelial growth factor receptor-2 in breast cancer. Biochim Biophys Acta. 2010 Aug;1806(1):108-21.

152 Higgins KJ, Liu S, Abdelrahim M, Vanderlaag K, Liu X, Porter W, et al. Vascular endothelial growth factor receptor-2 expression is down-regulated by 17beta-estradiol in MCF-7 breast cancer cells by estrogen receptor alpha/Sp proteins. Mol Endocrinol. 2008 Feb;22(2):388-402.

153 Higgins KJ, Liu S, Abdelrahim M, Yoon K, Vanderlaag K, Porter W, et al. Vascular endothelial growth factor receptor-2 expression is induced by 17beta-estradiol in ZR-75 breast cancer cells by estrogen receptor alpha/Sp proteins. Endocrinology. 2006 Jul; 147(7):3285-95.
154 Liang Y, Brekken RA, Hyder SM. Vascular endothelial growth factor induces proliferation of breast cancer cells and inhibits the anti-proliferative activity of anti-hormones. Endocr Relat Cancer. 2006 Sep;13(3):90519.

155 Linderholm BK, Hellborg H, Johansson U, Elmberger G, Skoog L, Lehtiö J, et al. Significantly higher levels of vascular endothelial growth factor (VEGF) and shorter survival times for patients with primary operable triple-negative breast cancer. Ann Oncol. 2009 Oct;20(10):1639-46.

156 Brummer G, Fang W, Smart C, Zinda B, Alissa N, Berkland C, et al. CCR2 signaling in breast carcinoma cells promotes tumor growth and invasion by promoting CCL2 and suppressing CD154 effects on the angiogenic and immune microenvironments. Oncogene. 2020;39(11):2275-89.

157 Kim D, Lee J, Kang J, Kim SH, Yoo TK, Oh S, et al. Notch1 in Tumor Microvascular Endothelial Cells and Tumoral miR-34a as Prognostic Markers in Locally Advanced Triple-Negative Breast Cancer. J Breast Cancer. 2019 Dec;22(4):562-78.
158 Saponaro C, Malfettone A, Ranieri G, Danza K, Simone G, Paradiso A, et al. VEGF, HIF$1 \alpha$ expression and MVD as an angiogenic network in familial breast cancer. PLoS One. 2013;8(1):e53070

159 Bos R, Zhong H, Hanrahan CF, Mommers EC, Semenza GL, Pinedo HM, et al. Levels of hypoxia-inducible factor-1 alpha during breast carcinogenesis. J Natl Cancer Inst. 2001 Feb;93(4):309-14.

160 Gupta AK, Joshi MB, Philippova M, Erne P, Hasler P, Hahn S, et al. Activated endothelial cells induce neutrophil extracellular traps and are susceptible to NETosis-mediated cell death. FEBS Lett. 2010 Jul;584(14): 3193-7.

161 Snoderly HT, Boone BA, Bennewitz MF Neutrophil extracellular traps in breast cancer and beyond: current perspectives on NET stimuli, thrombosis and metastasis, and clinical utility for diagnosis and treatment. Breast Cancer Res. 2019 Dec;21(1): 145.

162 Walker AJ, West J, Card TR, Crooks C, Kirwan CC, Grainge MJ. When are breast cancer patients at highest risk of venous thromboembolism? A cohort study using English health care data. Blood. 2016 Feb;127(7): 849-57. 